\title{
Anti-apoptotic protein Lifeguard does not act as a tumor marker in breast cancer
}

\author{
VIKTOR MAURER ${ }^{1}$, KERSTIN REIMERS ${ }^{1}$, HANS J. LÜCK $^{2}$, PETER M. VOGT $^{1}$ and VESNA BUCAN ${ }^{1}$ \\ ${ }^{1}$ Department of Plastic, Hand and Reconstructive Surgery, Hanover Medical School, D-30652 Hanover; \\ ${ }^{2}$ Gynecologic Oncology Practice, D-30177 Hanover, Germany
}

Received April 1, 2015; Accepted September 2, 2016

DOI: $10.3892 / \mathrm{ol} .2017 .5658$

\begin{abstract}
The aim of the present study was to use an enzyme-linked immunosorbent assay (ELISA) to determine the concentrations of Lifeguard (LFG) protein in the serum of 36 patients diagnosed with breast cancer and to compare these values with the concentrations of LFG protein in the serum of 7 healthy volunteers in order to detect a possible association between the expression of LFG in the serum and the degree of malignancy of the disease. Although there is no direct association between the LFG protein concentration in the serum and the degree of malignancy of breast cancer, a statistically significant distribution of the concentration in all investigated samples was observed. This indicated an association between the LFG protein concentration in human serum with a currently unknown factor.
\end{abstract}

\section{Introduction}

In 1785, Johann Heinrich Jänisch created one of the first studies of a disease that triggers up to 14 million new cases worldwide per year: Cancer (1). Statistics published by the World Health Organization (WHO) in 2014 list the most common localizations of tumors (1). In men, by far the most common cancer, accounting for $16.7 \%$ of cancer cases, occurs in the lungs, followed by prostate cancer, accounting for $15.0 \%$ of cases, and colorectal cancer, accounting for $10.0 \%$ of cancers. In women, lung cancer accounts for $8.7 \%$ of cancer cases, but mostly the mammary gland is affected, accounting for $25.2 \%$ of cancers (1). In 2010 alone, there were $>70,000$ new cases of breast cancer diagnosed in Germany. Statistically, 1 in 8 women develop breast cancer during their lives (2). Although the mortality rate has demonstrated a decreasing trend in the past decade, in 2014, 89,300 breast

Correspondence to: Dr Vesna Bucan, Department of Plastic, Hand and Reconstructive Surgery, Hanover Medical School, 21 Feodor-Lynen Street, D-30652 Hanover, Germany

E-mail: bucan.vesna@mh-hannover.de

Key words: breast cancer, Lifeguard, tumor marker cancer-associated mortalities were predicted across the EU (3). An early detection is essential for successful treatment of the disease. The survival rate increases significantly with early detection of the tumor (4). With screening methods such as mammography screening, an early diagnosis is possible; however, $48 \%$ of all diagnosed tumors in the mammary gland are already in an advanced stage of disease at the time of diagnosis. Identification of tumors at an early time point is therefore just as important as devising new therapies to further curb the disease $(2,3)$.

In previous years, the protein Lifeguard (LFG) has been associated with breast cancer (5-7). In certain cells, increased expression of this protein in vitro resulted in a failure of programmed cell death. In human tissue, increased expression was detected, particularly in breast cancer cells (8). In addition, the $\mathrm{C}$-terminal shortened $\beta$-isoform has enhanced expression in breast cancer cells and tissues. Notably, primary breast cancer cell lines and tumor tissues showed a stronger expression of the isoform compared with established cell lines, in which the longer isoform was strongly expressed. The isoform of the protein may also protect cells of the mammary gland from apoptosis and result in an increase in gene expression of members of the Akt signaling pathway (9).

Furthermore, it was demonstrated that LFG is regulated by the lymphoid enhancer-binding factor 1 (LEF-1) transcription factor, whereas LEF-1 is activated via the phosphoinositide 3-kinase (PI3K)/Akt pathway and interacts with membrane-bound phosphatidylinositol lipids that are also involved in the phosphorylation and activation of Akt kinase (5). In follow-up studies, the expression of the LFG protein was successfully suppressed by the use of specific small interfering (si)RNA against the LFG transcript and the LEF-1 transcript $(5,6)$. The siRNA-transfected cells showed significantly increased apoptosis in the presence of perifosine and the chemotherapeutic agents erlotinib and trastuzumab in breast carcinoma and sarcoma cell lines $(6,7)$. Bucan et al identified tripartite motif-containing protein 21 (TRIM21) as an interaction partner of LFG (8). TRIM21 is a protein composed of 4 domains that plays a role in the regulation of gene expression $(10,11)$. The present study aims to verify whether the disease degree of breast cancer is associated with the LFG protein concentration in the serum of patients. 


\section{Materials and methods}

Enzyme-linked immunosorbent assay (ELISA). From April 2015 until May 2016, samples from breast cancer patients and healthy volunteers were collected in association with Professor Lück (Gynecologic Oncology Practice, Hanover, Germany), and the concentration of LFG protein in serum was assessed. Approval for the present study was obtained from the Hannover Medical School's institutional review board (Hanover, Germany). Informed consent was provided according to the Declaration of Helsinki. The study participants included 36 patients with breast cancer and 7 healthy volunteers. Informed consent was obtained from all subjects.

The concentration of LFG protein in the serum of the patients and volunteers was assessed with a FAIM2 ELISA kit (MyBioSource, Inc., San Diego, CA, USA), which was used in accordance with the manufacturer's protocol. A double determination was performed on 36 patients. In addition, 14 wells of a 96-well plate were filled with the serum of healthy volunteers. All sera were stored at $-20^{\circ} \mathrm{C}$ prior to use. A positive control of $150 \mathrm{ng} / \mu \mathrm{l}$ pure LFG protein was added to 2 wells. In order to accurately identify the concentration, a standard was created according to the manufacturer's protocol for the ELISA kit, which may indicate a concentration between 39,063 and 2,500 $\mathrm{pg} / \mathrm{ml}$. Following addition of all the samples and a subsequent $2 \mathrm{~h}$ incubation at $37^{\circ} \mathrm{C}$, a biotin antibody was added and again incubated for $1 \mathrm{~h}$ at $37^{\circ} \mathrm{C}$. Subsequent to several washing steps, horseradish peroxidase-avidin (eBioscience, Inc., San Diego, CA, USA) was added to each well and incubated for $1 \mathrm{~h}$ at $37^{\circ} \mathrm{C}$. Subsequent to washing, 3,3',5,5'-tetramethylbenzidine substrate (Sigma-Aldrich; Merck Millipore, Darmstadt, Germany) was added to each well and incubated in the dark for $30 \mathrm{~min}$ at $37^{\circ} \mathrm{C}$. Finally, this was followed by the measurement of the fluorescence signals of the plate at a wavelength of $450 \mathrm{~nm}$ with a GENios plate analyzer (Tecan, Männedorf, Switzerland).

Statistical analysis. The data obtained were analyzed with Origin software version 9 (OriginLab Corporation, Northampton, MA, USA). All experiments were performed in triplicate and repeated at two independent time points. Data are presented as the mean \pm standard deviation. $\mathrm{P}<0.05$ was considered to indicate a statistically significant difference.

\section{Results}

Investigation and statistical evaluation of measured values. Measurement with the ELISA kit was performed to assess whether an association exists between the concentration of LFG protein in the serum of patients and characteristic properties of breast cancer. Therefore, the concentration of LFG protein in the serum of 36 patients diagnosed with breast cancer and the concentrations in the serum of 7 healthy volunteers were assessed. The measurement of LFG serum concentration was performed by detecting the optical density (OD) of the serum samples. The $\mathrm{OD}_{450}$ values are shown in Tables I and II.

In order to convert the $\mathrm{OD}_{450}$ values in the corresponding concentrations, the preparation of a calibration curve based on the standard was necessary. This is shown in Fig. 1. It was essential that the straight line extended through the origin, as this ensures that, in the samples in which the solvent is present exclusively, a corresponding $\mathrm{OD}_{450}$ of 0 is obtained. The conversion factor of $\mathrm{OD}_{450}$ to the concentration $(\mathrm{ng} / \mathrm{ml})$ was performed using the following equation:

$$
\mathrm{c}(\text { sample })=\mathrm{OD}_{450} \times(0.84 \pm 0.073)
$$

where $\mathrm{c}$ was the concentration in $\mathrm{ng} / \mathrm{ml}$ and $\mathrm{OD}_{450}$ was the $\mathrm{OD}$ measured at a wavelength of $450 \mathrm{~nm}$.

Using the calibration curve, the serum LFG concentrations of patients and healthy subjects was determined. The OD values for the 36 patients are reported in Table III. Each element of Table III corresponds to the average LFG concentration of a duplicate determination in serum of the respective patients.

Table IV reports the average LFG concentrations of a duplicate determination in serum of healthy subjects, as well as the measurements for the positive control. To visualize an overview of the spread of the values, a box plot was prepared for each group of patients and healthy volunteers, which are shown in Figs. 2 and 3.

The resulting calculated statistical values are listed in Table V. In each measurement, the standard deviation was extremely large. The standard deviation in the patient group was almost $40 \%$ of the mean value; in healthy subjects the standard deviation was $\sim 41 \%$ of the mean. While the average value in healthy volunteers was $0.03 \mathrm{ng} / \mathrm{ml}$ higher than the average value in patients, the median was similar in the patient group and healthy volunteers, at $16.8-17.1 \mathrm{ng} / \mathrm{ml}$. When comparing Figs. 2 and 3, a significantly larger span was observed in the patients, as well as the lower interval in which the upper quartile is located. The histograms of each frequency distribution are shown in Figs. 4 and 5.

The interval width $\Delta \mathrm{x}$ was derived by dividing the breadth by the number of intervals, as follows:

$$
\Delta \mathrm{x}(\mathrm{ng} / \mathrm{ml})=\text { breadth } / \sqrt{ } \mathrm{n}(\text { patients })=0.04885 \approx 0.05
$$

Thus, the value range was divided into 6 intervals on an identical length of $0.05 \mathrm{ng} / \mathrm{ml}$. These are shown in Table VI. As the box plots reveal, in the patients and healthy subjects there was no equal distribution over all intervals, but a clear maximum in one of the intervals. The maximum number of patients was in interval 1. Until interval 3, the frequency of concentrations steadily declined. The number of patients in interval 4 was slightly higher than interval 3. No patients demonstrated concentrations in interval 5 and only $5.7 \%$ of the measured values were classed as interval 6 .

A similar result is shown in the histogram of the healthy volunteers. The interval with the highest frequency was, however, interval 2. None of the measured values lay in intervals 1 or 4 . The remaining intervals 3, 5 and 6 reflect an equal distribution of $14.3 \%$.

Evaluation of measured values according to patient and tumor characteristics. Additional evaluation of the measured values was performed as a function of multiple attributes of the patients and breast cancer. These characteristics included: Age of the patients; type of histological finding; presence of various growth factors, consisting of progesterone and estrogen 
Table I. $\mathrm{OD}_{450}$ values of the standards, healthy volunteers and a positive control ${ }^{\mathrm{a}}$.

\begin{tabular}{ccccc}
\hline Standard $\left(\mathrm{OD}_{450}\right)$ & Standard $\left(\mathrm{OD}_{450}\right)$ & Healthy $\left(\mathrm{OD}_{450}\right)$ & Volunteers & Positive $\left(\mathrm{OD}_{450}\right)$ \\
\hline 0.000 & 0.1258 & 0.1763 & 0.2232 & 0.1442 \\
39.063 & 0.2423 & 0.4207 & 0.2790 & 0.134 \\
78.125 & 0.3427 & 0.2658 & 0.2600 & \\
156.250 & 0.4328 & 0.4259 & 0.4245 & 0.1740 \\
312.500 & 0.5058 & 0.1657 & 0.1818 & \\
625.000 & 1.1678 & 0.1676 & 0.2084 & \\
$1,250.000$ & 2.0601 & 0.1912 & & \\
$2,500.000$ & 2.5811 & & & \\
\hline
\end{tabular}

${ }^{a}$ In order to convert the $\mathrm{OD}_{450}$ values into the corresponding concentrations, the preparation of a calibration curve based on the standard protein concentration was necessary. The conversion factor of $\mathrm{OD}_{450}$ to concentration $(\mathrm{ng} / \mathrm{ml})$ was performed using the following equation: Concentration of sample $(\mathrm{ng} / \mathrm{ml})=\mathrm{OD}_{450} \mathrm{x}(0.84 \pm 0.073) / 50$. OD, optical density.

Table II. OD $_{450}$ values of 36 patients ${ }^{\mathrm{a}}$.

\begin{tabular}{lcccc}
\hline \multicolumn{2}{l}{ Patient samples $\left(\mathrm{OD}_{450}\right)$} & & & \\
\hline 0.2473 & 0.2823 & 0.1807 & 0.1608 & 0.2855 \\
0.2168 & 0.3487 & 0.1415 & 0.164 & 0.2764 \\
0.3808 & 0.4610 & 0.1675 & 0.2546 & 0.1293 \\
0.4523 & 0.4558 & 0.2197 & 0.2476 & 0.1436 \\
0.2194 & 0.3015 & 0.3447 & 0.1992 & 0.2694 \\
0.1945 & 0.3807 & 0.3127 & 0.2507 & 0.1210 \\
0.2007 & 0.1553 & 0.2719 & 0.1464 & 0.1327 \\
0.2077 & 0.1698 & 0.1314 & 0.1250 & 0.1307 \\
0.1389 & 0.1519 & 0.1998 & 0.1397 & \\
0.1571 & 0.1721 & 0.1638 & 0.1077 & \\
0.2967 & 0.2155 & 0.3027 & 0.1496 & \\
0.3198 & 0.3963 & 0.2724 & 0.1127 & \\
0.2324 & 0.1304 & 0.2471 & 0.1763 & \\
0.2406 & 0.1562 & 0.2301 & 0.2331 & \\
0.2267 & 0.1329 & 0.1573 & 0.1142 & \\
0.2206 & 0.1584 & 0.1624 & 0.1074 &
\end{tabular}

a Lifeguard serum concentration determination was performed by detecting the OD of the serum samples. OD, optical density.

receptors, and human epidermal growth factor receptor 2; Ki67 value; grade of the tumor; and size of the tumor and presence of lymph node involvement, as well as metastases.

In Fig. 6, the average measured serum LFG concentration of patients is shown as a function of their age. As an interval breadth, the root of the span width was taken:

$$
\Delta \mathrm{x}=\sqrt{ } \text { span width }=\sqrt{ } 79-30=7 \text { years }
$$

Due to the extremely high standard deviation, as well as the similar average values in almost all intervals, a uniform distribution of LFG protein concentration in all investigated ages may be assumed.

Fig. 7 shows the measured serum LFG concentration of the patients, depending on the histological findings of breast

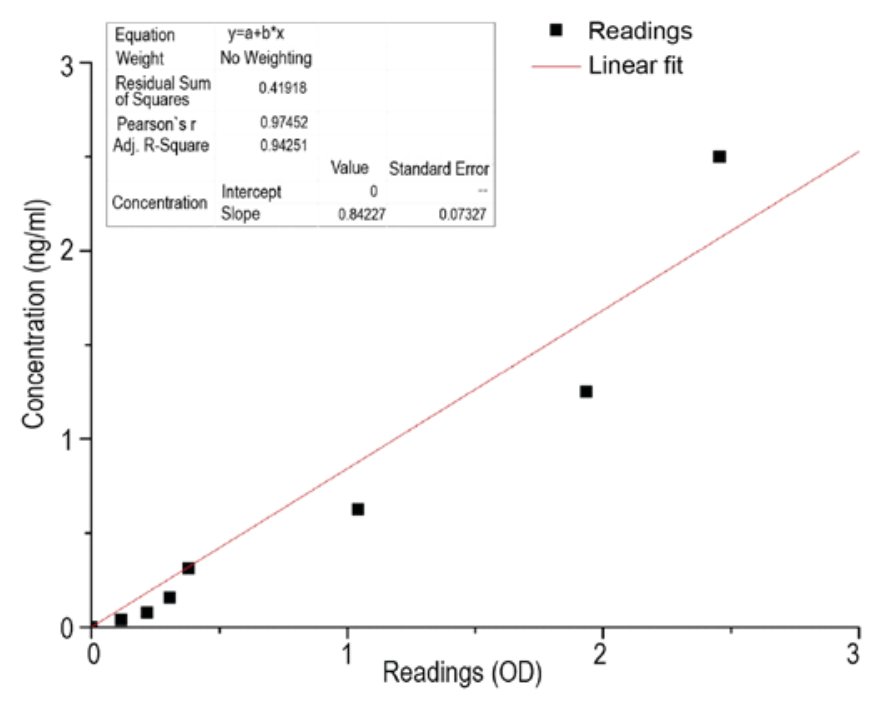

Figure 1. Calibration curve for converting the $\mathrm{OD}_{450}$ values at the respective concentration. OD, optical density.

cancer. The similar mean and the high standard deviations for the two possible types of findings indicate no direct association with the LFG protein concentration in the serum of patients. In Fig. 8, the measured concentration of patients depending on the detection of various types of receptors as growth factors is mapped.

In Fig. 8, it can be observed that the LFG protein concentration is not decisive on the presence of a receptor, as also in this approach an equal distribution of all arithmetic means and high standard deviations can be obtained. In Fig. 9, the measured concentration of patients is exhibited depending on the Ki67 value of breast cancer. As interval limits, the root of the maximum possible amount was taken for the Ki67 value:

$$
\Delta \mathrm{x}=\sqrt{ } \operatorname{Ki} 67(\text { maximum })=\sqrt{ } 100=10
$$

In Fig. 9, all bar heights for the individual intervals were of a similar value and the existing standard deviations had strong variances. Fig. 10 shows the measured concentration of LFG protein of the patients, depending on the grade of the tumor. 
Table III. Concentrations of Lifeguard protein in 36 patients with the standard deviation.

Patient samples, ng/ml

\begin{tabular}{lllll}
\hline $0.196 \pm 0.017$ & $0.266 \pm 0.023$ & $0.136 \pm 0.012$ & $0.137 \pm 0.012$ & $0.237 \pm 0.021$ \\
$0.351 \pm 0.030$ & $0.386 \pm 0.033$ & $0.163 \pm 0.014$ & $0.212 \pm 0.018$ & $0.115 \pm 0.010$ \\
$0.174 \pm 0.015$ & $0.287 \pm 0.025$ & $0.277 \pm 0.024$ & $0.190 \pm 0.016$ & $0.164 \pm 0.014$ \\
$0.172 \pm 0.015$ & $0.137 \pm 0.012$ & $0.170 \pm 0.015$ & $0.114 \pm 0.010$ & $0.111 \pm 0.010$ \\
$0.125 \pm 0.011$ & $0.137 \pm 0.012$ & $0.153 \pm 0.013$ & $0.104 \pm 0.009$ & $0.110 \pm 0.009$ \\
$0.260 \pm 0.023$ & $0.258 \pm 0.022$ & $0.242 \pm 0.210$ & $0.172 \pm 0.015$ & \\
$0.199 \pm 0.017$ & $0.121 \pm 0.011$ & $0.201 \pm 0.017$ & $0.093 \pm 0.008$ \\
$0.188 \pm 0.016$ & $0.123 \pm 0.011$ & $0.135 \pm 0.012$ & & \\
\hline
\end{tabular}

Table IV. Concentrations of Lifeguard protein in 7 healthy volunteers, as well as the positive control with the respective standard deviation.

\begin{tabular}{lc}
\hline Healthy volunteers, $\mathrm{ng} / \mathrm{ml}$ & Positive control, $\mathrm{ng} / \mathrm{ml}$ \\
\hline $0.168 \pm 0.015$ & $0.117 \pm 0.009$ \\
$0.295 \pm 0.026$ & \\
$0.221 \pm 0.019$ & \\
$0.358 \pm 0.031$ & \\
$0.143+0.012$ & \\
$0.147 \pm 0.013$ & \\
$0.168 \pm 0.015$ & \\
\hline
\end{tabular}

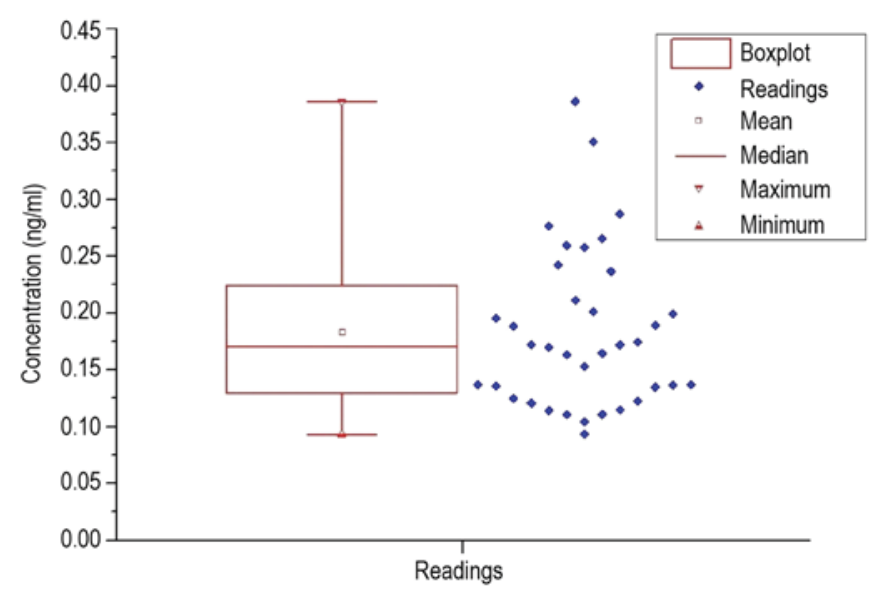

Figure 2. Box plot of the concentrations of Lifeguard protein in the serum of patients.

In Fig. 10, it was also shown that each bar was of a similar value and each bar had a large standard deviation. Fig. 11 shows the measured concentration of the patients depending on the properties of the different stages of cancer.

In Fig. 11, with the exception of the concentrations of the measurements $\mathrm{N} 1$ and N2, all bars were approximately the same value. The bar N1 shows a concentration of $0.253 \mathrm{ng} / \mathrm{ml}$, which is higher than any other. The level of the N2 bar is the lowest at $0.131 \mathrm{ng} / \mathrm{ml}$. With the exception of M1, N2 and T3, all standard deviations are at a value of at least $\pm 0.05 \mathrm{ng} / \mathrm{ml}$.

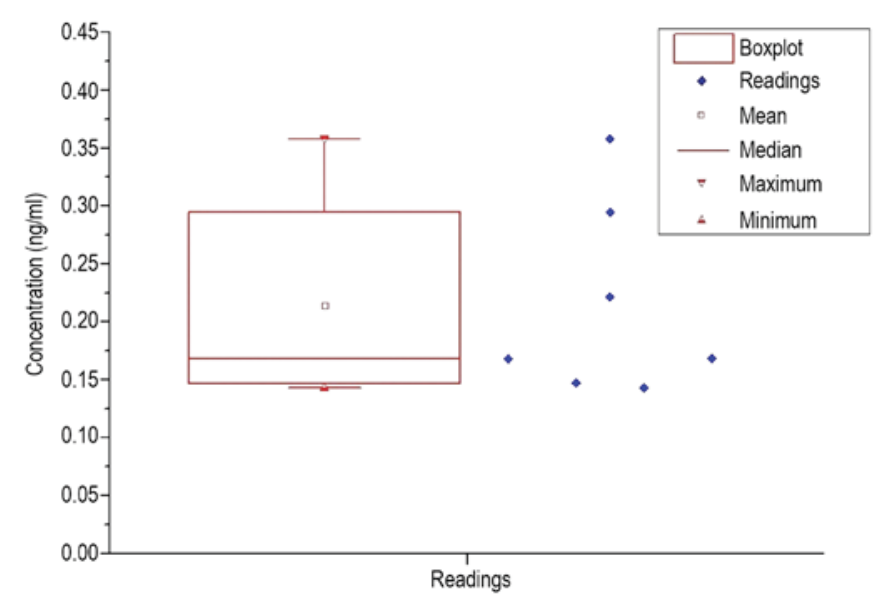

Figure 3. Box plot of the concentrations of Lifeguard protein in the serum of healthy volunteers.

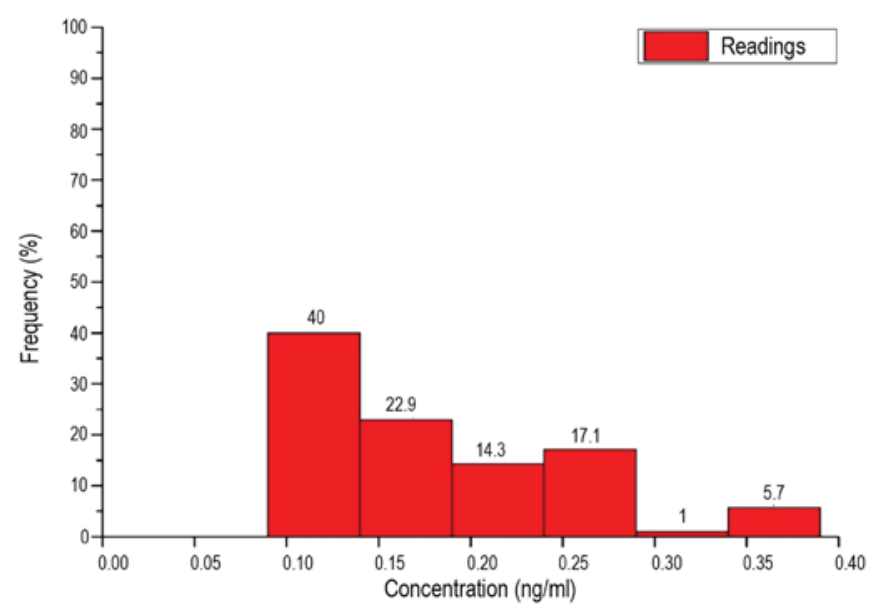

Figure 4. Histogram of the concentration of Lifeguard protein in the serum of patients.

The standard deviation of $\mathrm{N} 2$ and T3 is $0.03 \mathrm{ng} / \mathrm{ml}$. The standard deviation of M1 is $0.015 \mathrm{ng} / \mathrm{ml}$, and the lowest of all the standard deviations.

\section{Discussion}

In the box plots of Figs. 2 and 3, as well as in the histograms of Figs. 4 and 5, it can be observed that the LFG concentration 
Table V. Statistical parameters of two measurements of the mean concentration value of Lifeguard protein (all data are provided in $\mathrm{ng} / \mathrm{ml})$.

\begin{tabular}{lcccccc}
\hline Group & Mean & $\begin{array}{c}\text { Standard } \\
\text { deviation }\end{array}$ & Media & Minimum & Maximum & Number \\
\hline Patients & 0.184 & 0.070 & 0.171 & 0.093 & 0.386 & 36 \\
Healthy individuals & 0.214 & 0.083 & 0.168 & 0.143 & 0.358 & 7 \\
\hline
\end{tabular}

Table VI. Interval breadths in the histograms.

\begin{tabular}{lccccrr}
\hline Measurement & Interval 1 & Interval 2 & Interval 3 & Interval 4 & Interval 5 & Interval 6 \\
\hline Breadth, ng/ml & $0.09-0.14$ & $0.14-0.19$ & $0.19-0.24$ & $0.24-0.29$ & $0.29-0.34$ & $0.34-0.39$ \\
\hline
\end{tabular}

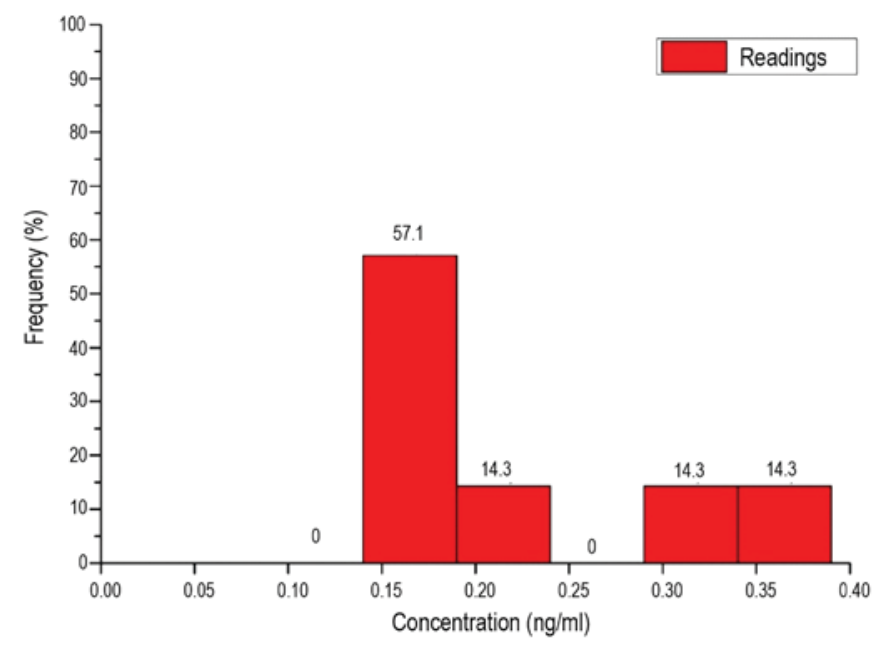

Figure 5. Histogram of the concentration of Lifeguard protein in the serum of healthy volunteers.

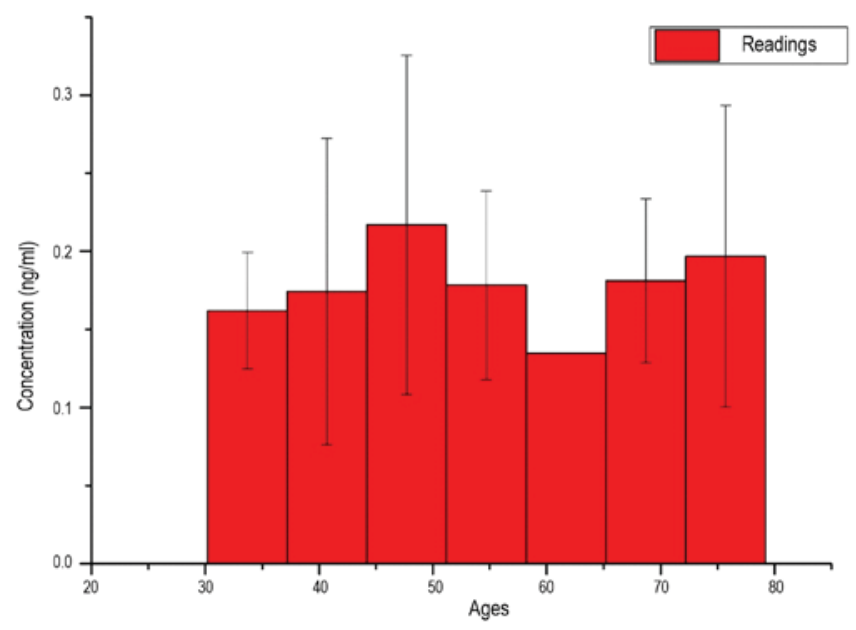

Figure 6. Measured concentration of Lifeguard protein depending on the age of the patients.

in the serum of patients and also from healthy volunteers is not arbitrarily large, but dependent on a previously unknown subject. The mean LFG protein concentration in the serum

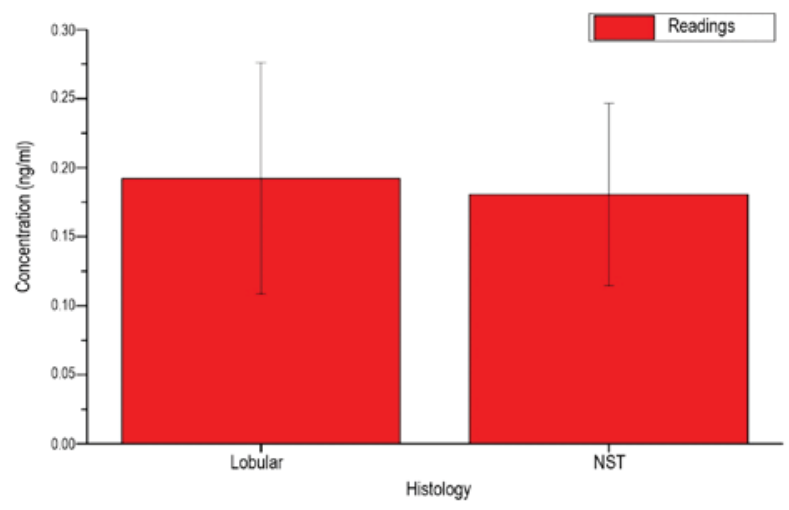

Figure 7. Measured concentration of Lifeguard protein depending on the histological findings of breast cancer.

of all samples was $0.1-0.2 \mathrm{ng} / \mathrm{ml}$, with certain exceptions $(\leq 0.39 \mathrm{ng} / \mathrm{ml})$. The histograms do not contain an equal distribution of concentration over the entire intervals, but instead demonstrate a maximum at an interval followed by lower concentrations in higher intervals. Comparing the two histograms, the frequency distribution appears to be similar, which initially does not indicate a direct function of the LFG protein concentration in the serum of patients with the characteristics of breast cancer.

The LFG protein concentration in the serum of patients is presented in Figs. 7-10. Although there are differences between certain average values of concentrations, the standard deviation of all measured values is too high, as that there may be an association between the LFG protein concentration and a property.

Fig. 10 shows that tumor size and the occurrence of metastasis are not directly associated with the concentration of LFG protein in the serum. Although the average concentrations in patients without metastases is higher than in patients with metastatic disease, there is such a large standard deviation in the measurements of the patients without metastases that no clear dependence can be detected. Additionally, only three readings of patients with metastases were available for measurements, and therefore no statistically significant differences were identified. A similar problem appears with the values of the patients with 


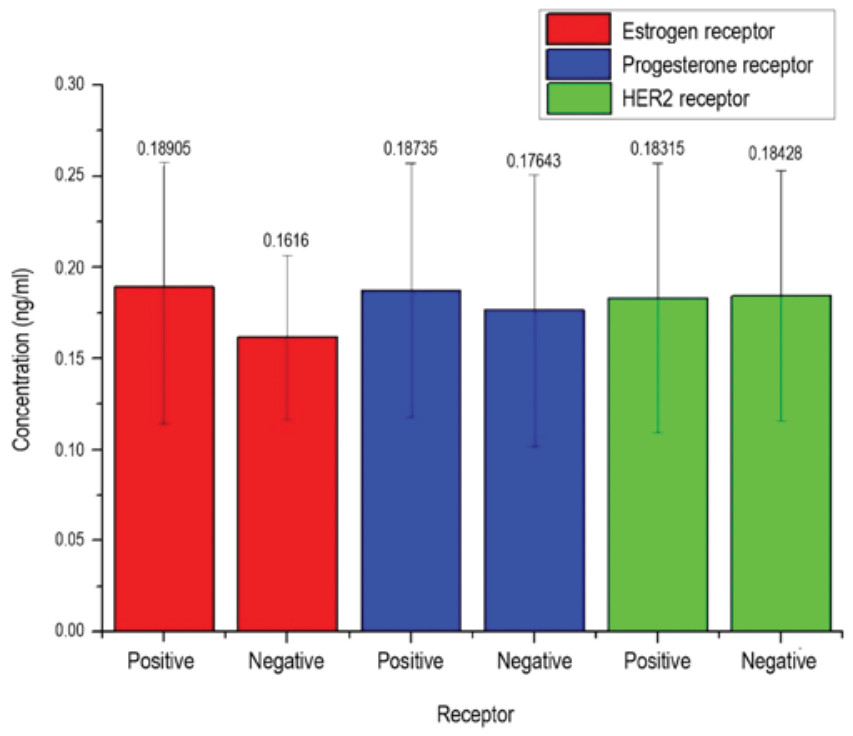

Figure 8. Measured concentration of Lifeguard protein, depending on the occurrence of estrogen-, progesterone- and HER2-receptors. HER2, human epidermal growth factor receptor 2

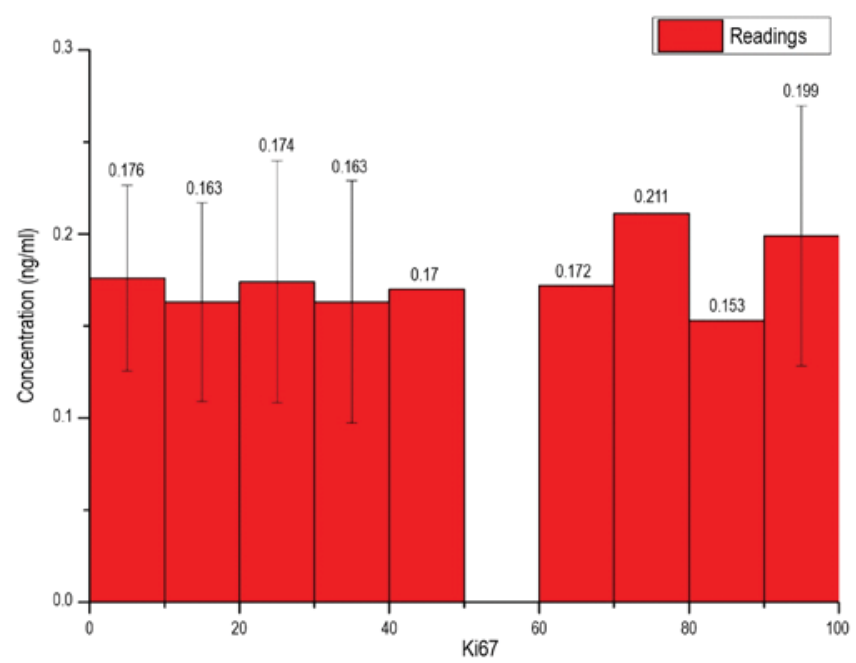

Figure 9. Measured concentration of Lifeguard protein as a function of Ki67 value of the tumor (in \%).

lymph node involvement. The mean values show the tendency that with a low involvement level of the lymph node (N1), a higher LFG protein concentration is present in the serum compared with no (N0) or higher lymph node involvement (N2 + N3). By contrast, the standard deviations are high. Furthermore, there were only 4 samples available for N1, 3 samples for N2 and 6 samples for $\mathrm{N} 3$, so that an insufficient statistical significance exists in the present analysis.

Fig. 6 shows that the concentration of LFG protein in the serum of the patients is also not dependent on the age of patients, since there is an equal distribution across all ages. Also, in this measurement there were too few samples available for the age groups, with low or no standard deviation to underline a statistical significance.

Despite the results of the histograms, Tables I and II must be observed critically as there is a high variance within several duplicate determinations in certain cases. In one case,

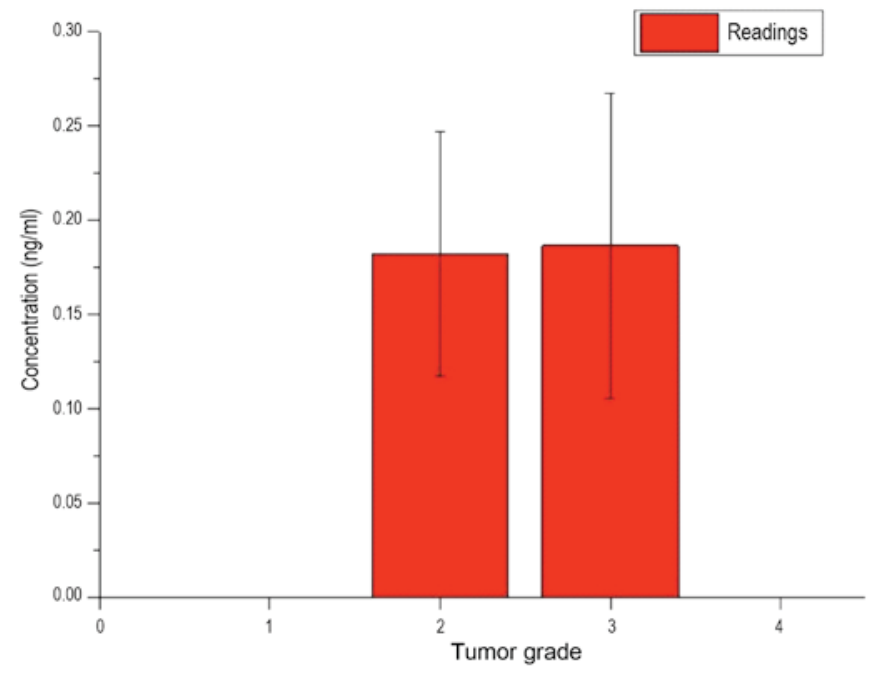

Figure 10. Measured concentration of Lifeguard protein depending on the grade of the tumor.

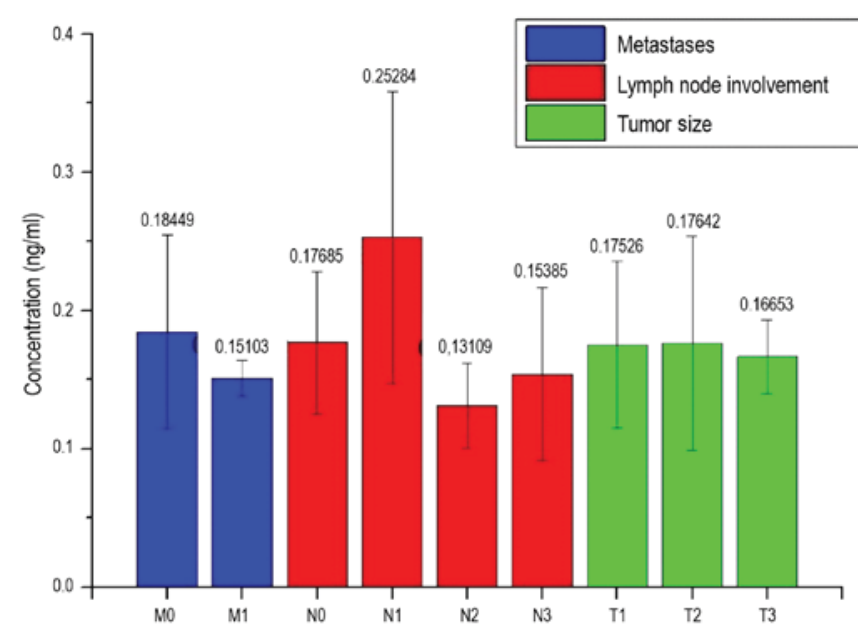

Figure 11. Measured concentration of Lifeguard protein depending on the appearing of metastasis, lymph node involvement and tumor size.

concentrations of $0.2155 \mathrm{ng} / \mathrm{ml}$ and $0.3863 \mathrm{ng} / \mathrm{ml}$ were determined, resulting in a difference of $0.181 \mathrm{ng} / \mathrm{ml}$. Assessing the other readings, this difference in results is extremely high and is likely to be caused by errors in the experimental procedure. The fluorometer GENios Tecan, which was used to determine the $\mathrm{OD}_{450}$ values, could have performed an erroneous measurement. However, since a value of $0.12 \mathrm{ng} / \mathrm{ml}$ was determined for the positive control and thus only a difference of $0.03 \mathrm{ng} / \mathrm{ml}$ is present from the true value, this possibility can be excluded. The general failure of the method can also be excluded due to the correct measurement of the standard; however, the possibility that an erroneous measurement was performed in individual wells remains. With the exception of that possibility, the ELISA kit used is described as highly sensitive, so small errors may have a major impact on the result. In particular, the washing steps subsequent to drying are described with numerous possible error sources, as not only a certain degree of care, but also a fast working speed is required.

The present results demonstrate that a discrete concentration of LFG protein is present in the human serum. Taking into 
account that LFG is a transmembrane protein and, accordingly, assumes a large extent of cellular functions, this is a significant identification.

Using the ELISA kit, a direct association between the LFG protein concentrations in the serum of patients and various characteristics of breast cancer was excluded. Thus, the initial hypothesis to use the LFG protein concentration in the serum as a tumor marker for the diagnosis of breast cancer cannot be realized. However, the histograms demonstrate distinct maxima, which indicate an association with a currently unknown factor. Thus, further investigation is required. For example, additional examination of the association between other medical conditions, such as rheumatoid arthritis or diabetes, as well as everyday habits such as diet and smoking as aspects associated with LFG protein concentration in the serum. Therefore, additional research on the origin of the LFG protein concentration in the serum may provide important insights into the human biological function and operation of the LFG protein.

\section{Acknowledgements}

The present study was funded by the Niedersächsische Krebsgesellschaft (Hanover, Germany; grant number B/Sc). The authors are grateful to Ms. Andrea Lazaridis (Hanover Medical School, Hanover, Germany) for her excellent technical assistance.

\section{References}

1. Stewart BW and Wild CP (eds): World Cancer Report 2014. IARC Publications, Lyon, 2014.

2. Robert Koch Institute and the Association of Population-Based Cancer Registries in Germany: Cancer in Germany 2009/2010. 9th edition. Robert Koch Institute, Berlin, 2013 (In German).

3. Malvezzi M, Bertuccio P, Levi F, La Vecchia C and Negri E: European cancer mortality predictions for the year 2014. Ann Oncol 25: 1650-1656, 2014.

4. Weinberg RA: The Biology of Cancer. 2nd edition. Garland Science, New York, NY, p25, 2013.

5. Bucan V, Adili MY, Choi CY, Eddy MT, Vogt PM and Reimers K: Transactivation of Lifeguard (LFG) by Akt-/LEF-1 pathway in MCF-7 and MDA-MB 231 human breast cancer cells. Apoptosis 15: 814-821, 2010.

6. Bucan V, Choi CY, Lazaridis A, Vogt PM and Reimers K: Silencing of anti-apoptotic transmembrane protein lifeguard sensitizes solid tumor cell lines MCF-7 and SW872 to perifosine-induced cell death activation. Oncol Lett 2: 419-422, 2011.

7. Gratzke AL, Reimers K, Vogt PM and Bucan V: Sensitising breast cancer cells to chemotherapy by downregulation of Lifeguard. Cancer Sci Ther 6: 411-416, 2014.

8. Bucan V, Mandel K, Bertram C, Lazaridis A, Reimers K, Park-Simon TW, Vogt PM and Hass R: LEF-1 regulates proliferation and MMP-7 transcription in breast cancer cells. Genes Cells 17: 559-567, 2012.

9. Dastagir N, Lazaridis A, Dastagir K, Reimers K, Vogt PM and Bucan V: Role of lifeguard $\beta$-isoform in the development of breast cancer. Oncol Rep 32: 1335-1340, 2014.

10. Wada K, Niida M, Tanaka M and Kamitani T: Ro52-mediated monoubiquitination of IKK $\beta$ down-regulates NF- $\kappa B$ Signalling. J Biochem 146: 821-832, 2009.

11. Freemont PS: RING for destruction? Curr Biol 10: R84-R87, 2000. 